\title{
Outcome of monocular surgery for horizontal strabismus in Hyderabad
}

This article was published in the following Dove Press journal:

Clinical Ophthalmology

2 April 2010

Number of times this article has been viewed

\author{
Sameen A Junejo \\ Munawar A Ansari \\ Liaquat University of Medical \\ and Health Sciences/Jamshoro, \\ Hyderabad-Sindh, Pakistan
}

Correspondence: Sameen Afzal Junejo House No: 100 Muslim Co-Operative Housing Society, Qasimabad-Hyderabad, Sindh Pakistan

$\mathrm{Tel}+92022$ 92I 035।

Fax +92 022265 II 93

Email sameenafzalI@gmail.com
Background and objective: Squint surgery is frequently performed successfully in Hyderabad. However, no study in any detail has been performed on the outcome of monocular surgery for horizontal squint in the region. This study aims to determine the results of monocular surgery for horizontal trabismus.

Design: Retrospective/observational study.

Subjects and methods: The study was conducted on patients aged under 45 years, presenting with horizontal strabismus and undergoing monocular squint surgery. Anterior segment slit lamp examination, and if possible, posterior segment examination with 90 diopter (D) and $78 \mathrm{D}$ fundoscopes was performed. Angle of deviation was measured. Patients were divided into two groups (esotropia and exotropia). Investigations were performed. Surgery was done under general anesthesia. A second surgical procedure was performed after six months for any residual deviations.

Results: After squint surgery, patients in group 1 (79\%) and in group 2 (73.3\%) had residual deviation of less than 15 prism diopters (PD). The preoperative deviations of $60 \mathrm{PD}$ or less illustrated excellent domino effects with residual deviation of fewer than 15 PD. Three patients with successive deviation underwent a second surgery with excellent outcomes.

Conclusion: Few extraocular muscles can be prevented due to monocular squint surgery when multiple surgeries are needed.

Keywords: horizontal strabismus, monocular surgery, Hyderabad

\section{Introduction}

Strabismus is a commonly recurrent clinical condition of ocular misalliance leading to deviation of the visual axis from bifoveal fixation, and is infrequently allied with developmental craniofacial incongruity, and certain neurological diseases such as cerebral palsy.

The worldwide incidence of strabismus varies from $3 \%$ to $5 \%,{ }^{1,2}$ whereas $\mathrm{Hu}$ and colleagues ${ }^{3}$ identified strabismus in $2 \%$ to $4 \%$ of white populations, and Abrahamsson and colleagues ${ }^{4}$ reported strabismus in $0.6 \%$ of Asians ${ }^{3}$ and Africans. ${ }^{5}$ In a study conducted by Dana and colleagues 5 in Sydney, the incidence of strabismus was established in 48 patients ( $2.8 \%$ of total population). In another study carried out by Donnelly and colleagues, the prevalence was 3.98\%. ${ }^{6}$ In an analysis conducted amongst Afghan immigrants in Pakistan, strabismus was noticed in $1.4 \%$ of patients. ${ }^{7}$ Another study conducted at Peshawar in 2004 confirmed that the total frequency of squint was $2 \%{ }^{8}$

The clinical treatment of squint includes evaluation and correction of multiple errors of refraction, management of amblyopia, and surgical treatment. The first surgery on

submit your manuscript | www.dovepress.com 
squint was executed in 1839 by a general surgeon, Johann Dieffenbach. ${ }^{9}$

The ocular realignment of visual axis by surgical intervention becomes necessary when conservative management is unsuccessful. Surgical interventions are able to improve diplopia, rectify three dimensional (3D) vision, broaden the visual field, and improve psychological status ${ }^{10}$ and cosmesis. $^{11}$

\section{Subjects and methods}

This is a retrospective clinical analysis conducted on the patients of both sexes with horizontal strabismus presenting for the first time from June 2004 to December 2007.

All patients suffering concomitant monocular horizontal squint (esotropia and exotropia), with deviation under 60 prism diopters (PD) devoid of any coupled vertical deviations were included in the study.

All subjects with history of paretic or limited extra ocular muscle component, more than 60 PD angle deviations, nystagmus, past history of any squint surgical procedure, and repeated deviation, were excluded from the current study.

Initial primary inspection of all patients was performed in our outpatient department by two qualified experienced ophthalmologists and four medical officers. After obtaining informed consent, the subjects were assessed for the following:

a) General history: including age, sex, citizenship, occupation, any history of corrective lenses, and which eye was affected. Photos of patients at up to the age of ten years were requested from patients and assessed to rule out any congenital anomaly.

b) Visual acuity of dominant (fixating) eye and squinting (nonfixating) eye, was evaluated with the help of Snellen's chart for educated subjects and an E-chart for uneducated children.

c) Slit lamp biomicroscopy, and applanation tonometry.

d) Indirect ophthalmoscopy by $90 \mathrm{D}$ and $78 \mathrm{D}$ fundoscopes with fully dilated pupils.

e) Ocular movements including versions and ductions in co-operative patients.

f) Measurement of deviation in PD for both distance and near vision. The divergence was calculated in patients with fine bilateral visual acuity by a prism and cover test for near $(33 \mathrm{~cm})$ and far $(6 \mathrm{~m})$ distance using a fixation object. The modified Krimsky test was used to measure deviation in patients with intense amblyopia, limited vision, or children younger than the age of five years.

g) In children, refraction under cycloplegia using cyclopentolate $1 \%$ eye drops was undertaken and any accommodative element of more than 2.0 D was excluded preoperatively.

Scheduled investigations at admission were examined thoroughly and included a complete blood picture, bleeding and clotting times, detailed urine analysis, and chest X-rays. All the patients and their attendants were fully informed of the postoperative results and probability of a subsequent surgery. A prophylactic antibiotic and ophthalmic drops, eg, ofloxacin and chloramphenicol, were administered every three to four hours the day surgery. A complete surgical procedure was carried out under general anesthesia after approval by consultation with a visiting physician and qualified anesthetist.

The surgical procedure consisted of monocular recession and resection of horizontal recti muscles of the nonfixing eye. The muscle was exposed by a limbal conjunctival incision with two radial relieving incisions. The muscle was then separated from its attachments by round-edge curved conjunctival scissors and destabilized by a muscle hook. Two 6'0 poly gelactin 910 absorbable sutures were used for two whip stitches; one at the upper border and other at the lower boundary of muscle in close proximity to its insertion point during recession, and far from the insertion point in the muscle cone during muscle resection. At the time of recession the muscle was incised in close proximity to its insertion point and during muscle resection, then it was incised far from its insertion point, finally the muscle was allowed to retract and draw back. Sutures were carried out of the conjunctival incision and left unfastened with one edge at the 12 o'clock position with the other in the opposite position. Recession was measured with a caliper from posteriorly at the beginning of the muscle insertion point and afterwards the muscle was sutured directly on the sclera by piercing the sclera with both the upper and lower suture needles opposite each other. Both needles were passed gently up to half the width of the sclera under resistance without penetrating deeply into uveal tissue. The uveal penetration was confirmed when the needle passed very easily through the sclera without resistance. As the sutures were tied, the retracted muscle was lifted and brought forward to be fastened to the attachment site, and it was sutured at its normal anatomical insertion point in case of resection. Absorbable sutures were used to close the conjunctiva. An antibiotic/steroid eye ointment (neomycin with betamethasone) was applied and the eye bandaged for 24 hours.

On every postoperative outpatient follow-up visit, a complete orthoptic assessment was performed, including visual acuity and a photograph of the patient to measure the angle of deviation. The final best-corrected visual acuity 
and angle of deviation was documented on a sixth month post-treatment follow up.

Secondary surgical procedures in the fixating eye for consecutive squint over 15 PDs were performed six months after initial surgery. The postoperative follow up compliance of study participants was excellent.

\section{Results}

Out of approximately 7000 ophthalmic patients, 87 (1.24\%) patients presented with strabismus during the study period. Out of these patients, 46 patients fulfilled the study inclusion criteria. Seven subjects refused to undergo surgical procedure, while the remaining 39 patients (esotropia $=24$ [61.5\%] and exotropia $=15$ [38.5\%]) were selected for surgery. The successful surgical outcome was considered as an angle deviation of 15 PDs or less at the six-month postoperative follow-up. Table 1 summarizes the general characteristics of patients of both groups.

Table 2 presents group 1 (esotropia) patient data including preoperative angles of deviation (Figure 1), surgical procedures and postoperative results (Figure 2). Table 3 presents group 2 (exotropia) patient data including all details (Figures 3 and 4).

In group 1 (esotropia), five patients (19.0\%) presented with residual deviation of more than 15 PDs. The remaining patients $(79.0 \%)$ presented with successful surgical outcomes. Similarly, in group 2 (exotropia), patients presented with orthophoria $(73.3 \%)$, while four $(26.7 \%)$ patients demonstrated residual deviation.

Three patients in both groups developed suture-related foreign body granuloma formation, which resolved within a few weeks during the course of treatment. Ocular movements, including convergence, were normal in all patients except

Table I General characteristics of patients with strabismus: $(\mathrm{n}=39)$

\begin{tabular}{|c|c|c|c|}
\hline Characteristic & & $\begin{array}{l}\text { Number of } \\
\text { patients }\end{array}$ & Percentage (\%) \\
\hline \multirow[t]{2}{*}{ Gender } & Male & 17 & 43.6 \\
\hline & Female & 22 & 56.4 \\
\hline \multirow[t]{3}{*}{ Age in years } & 5 to 15 & 16 & 41.0 \\
\hline & 16 to 30 & 13 & 33.4 \\
\hline & 31 to 45 & 10 & 25.6 \\
\hline \multirow[t]{2}{*}{ Residency } & Rural & 13 & 33.4 \\
\hline & Urban & 26 & 66.6 \\
\hline Use of lenses & & 14 & 35.9 \\
\hline \multirow[t]{3}{*}{ Financial status } & Upper & Nil & Nil \\
\hline & Middle & 17 & 43.5 \\
\hline & Lower & 22 & 56.5 \\
\hline
\end{tabular}

Table 2 Pre-and postoperative clinical characteristics of group I (esotropia)

\begin{tabular}{lllll}
\hline $\begin{array}{l}\text { Number } \\
\text { of patients }\end{array}$ & Age (years) & $\begin{array}{l}\text { Angle of } \\
\text { deviation } \\
\text { (PD) }\end{array}$ & $\begin{array}{l}\text { Post } \\
\text { operative } \\
\text { residual }\end{array}$ & $\begin{array}{l}\text { Surgical } \\
\text { technique }\end{array}$ \\
\hline 10 & 05 to 15 & $<15$ & 15 & RC of MR \\
& 8 patients & 2 patients & $5-6$ mm over all \\
& $>33.3 \%$ & $8.4 \%$ & RS of LR \\
& & & $7-9$ mm over all \\
8 & 16 to 30 & $<15$ & $>15$ & \\
& & 6 patients & 2 patients & \\
& & $25.0 \%$ & $8.4 \%$ & \\
6 & & $<15$ & $>15$ & \\
& 31 to 45 & 5 patients & 1 patient & \\
& & $20.7 \%$ & $4.2 \%$ & \\
\hline
\end{tabular}

Notes: $\mathrm{n}=24$ (61.5\%) Preoperative angle of deviation PD $=30$ to 60 overall. Abbreviations: PD, prism diopter; RC, recession; RS, resection; MR, medial rectus; $\mathrm{LR}$, lateral rectus.

two (13.4\%) in group 2, who underwent $10 \mathrm{~mm}$ recession of lateral rectus and experienced limitation in ocular movements. Muscle overcorrection was not encountered in either group. Out of 39 subjects, 12 patients were lost to follow-up, while the remaining 27 completed six months postoperative follow-up.

Of nine patients $(23.0 \%)$ in both groups who exhibited consequent strabismus after six months, six patients did not agree to a second surgery and only three patients underwent successful secondary surgical intervention.

\section{Discussion}

Monocular strabismus surgery is a recommended procedure for patients suffering monocular concomitant squint. This procedure minimizes the handling of the dominant eye, thereby reducing surgical duration. ${ }^{12,13}$

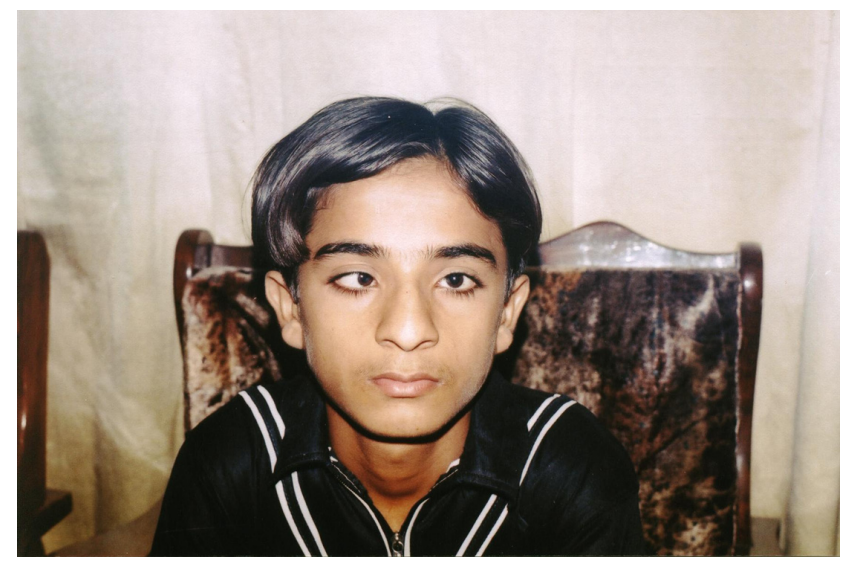

Figure I A I3-year-old boy with right eye concomitant strabismus. 


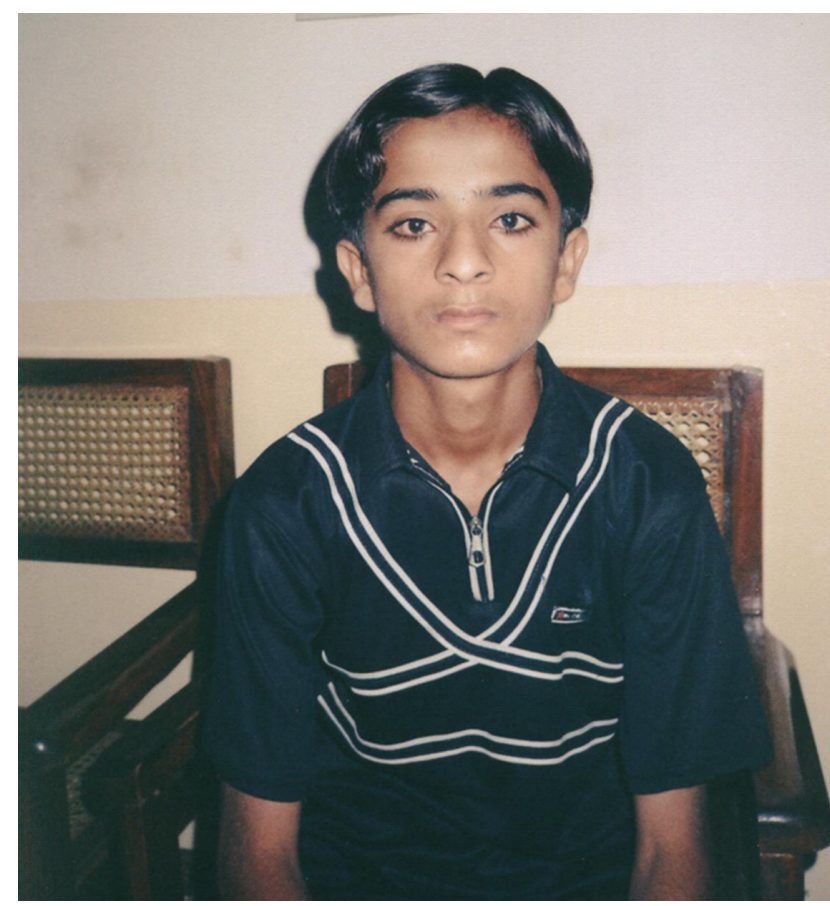

Figure 2 A I3-year-old boy underwent right monocular strabismus surgery (I5th postoperative day).

Occasionally it becomes difficult to visually align the eyes by operating only on one eye because of larger deviations of more than 60 PDs. At this stage, clinical circumstances for a second surgery on the fixing eye or binocular squint surgery concerning more than two horizontal rectus muscles is the main and extensive used clinical procedure. This technique also avoids limitations in ocular movement. ${ }^{14-16}$ In our study, we acquired excellent outcomes through a surgical procedure carried out on the fixating eye in subjects who

Table 3 Pre and post-operative clinical characteristics of group 2 (exotropia)

\begin{tabular}{lllll}
\hline $\begin{array}{l}\text { Number } \\
\text { of patients }\end{array}$ & $\begin{array}{l}\text { Age } \\
\text { (years) }\end{array}$ & $\begin{array}{l}\text { Angle of } \\
\text { deviation } \\
\text { (PD) }\end{array}$ & $\begin{array}{l}\text { Post- } \\
\text { operative } \\
\text { residual }\end{array}$ & $\begin{array}{l}\text { Surgical } \\
\text { technique }\end{array}$ \\
\hline 4 & 05 to I5 & $<15$ & $>15$ & RC of MR \\
& & 3 patients & I patients & 5-6 mm over all \\
& & $20.0 \%$ & $6.6 \%$ & RS of LR \\
6 & 16 to 30 & $<15$ & $>15$ & $7-9$ mm over all \\
& & 4 patients & 2 patients & \\
& & $26.7 \%$ & $13.4 \%$ & \\
5 & 31 to 45 & $<15$ & $>15$ & \\
& & 4 patients & I patient & \\
& & $26.7 \%$ & $6.6 \%$ & \\
\hline
\end{tabular}

Notes: $\mathrm{n}=15$ (38.5\%) Preoperative angle of deviation in PD $=30$ to 60 overall. Abbreviations: PD, prism diopter; $\mathrm{RC}$, recession; $\mathrm{RS}$, resection; $\mathrm{MR}$, medial rectus; $\mathrm{LR}$, lateral rectus.

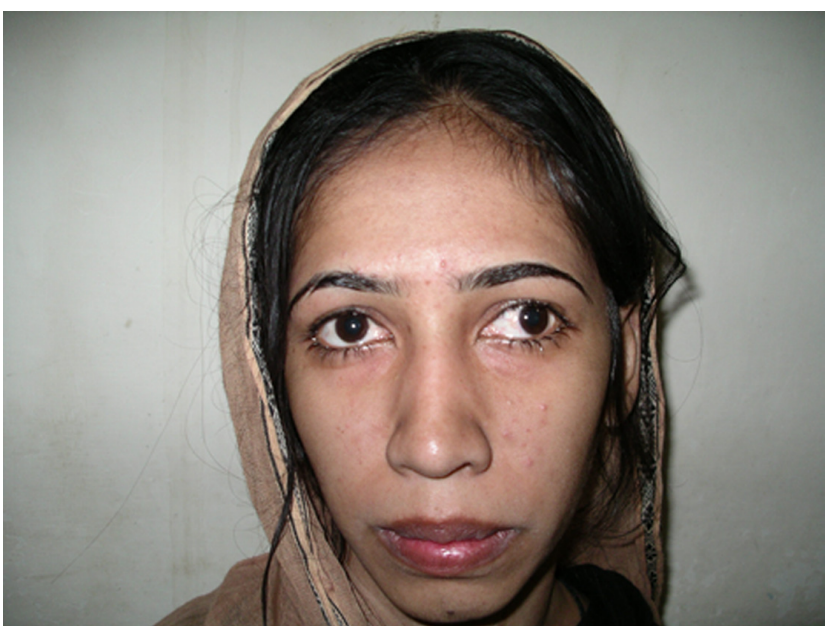

Figure 3 A 16-year-old girl with left eye concomitant strabismus.

had developed residual deviation after the initial surgery on the nondominant, fixating eye.

Monocular squint surgery can be safely performed in adults under peribulbar anesthesia, with rapid recovery and less complications. ${ }^{17,18}$ Although there are some disadvantages of regional anesthesia including: retrobulbar hemorrhage, optic nerve injury, central retinal artery occlusion, and ptosis. ${ }^{19}$ In this study all the subjects in both groups were operated under general anesthesia.

Scott and colleagues define the accuracy of squint surgery as a residual deviation of 10 PDs or less. Scott also states that for larger angles, the surgical objective should be a small residual deviation rather than straight eyes. ${ }^{20}$ Following this concept of undercorrection, the residual deviation of 15 PDs and less was considered accurate in this study.

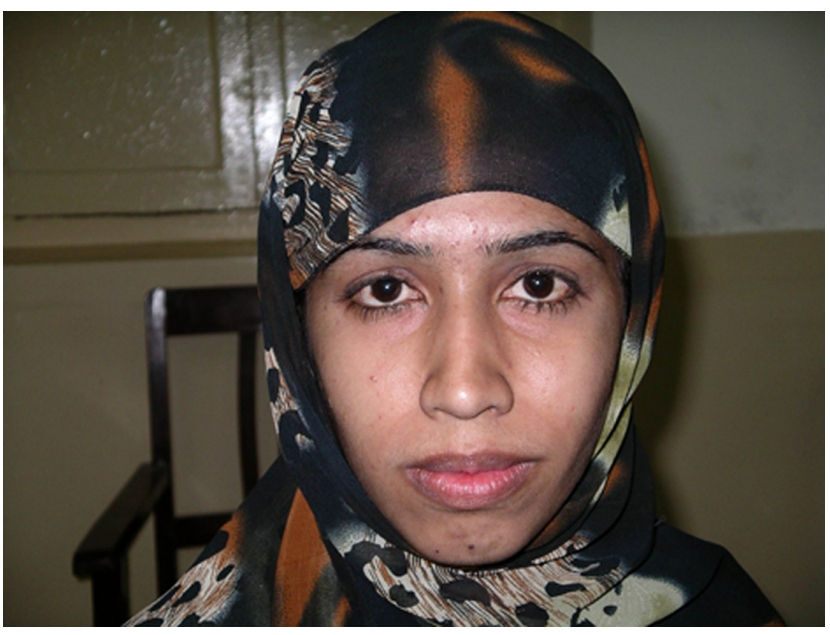

Figure 4 A 16-year-old girl underwent left monocular strabismus surgery (15th postoperative day). 
Restricted ocular movements are an occasional clinical problem following huge recessions. Multiple authors strongly recommend not exceeding a $7 \mathrm{~mm}$ recession on medial rectus and $8 \mathrm{~mm}$ recession on lateral rectus muscle to avoid diminished restricted ocular movements. ${ }^{21-23}$

In this study only two (13.4\%) subjects in group 2 , who underwent a $10 \mathrm{~mm}$ recession on lateral rectus muscle suffered postoperative limitation in ocular movements.

\section{Disclosures}

The authors report no conflicts of interest relevant to this research.

\section{References}

1. Arora A, Williums B, Arora AK. Decreasing strabismus surgery. $\mathrm{Br} J$ Ophthamol. 2005;89(4):409-412.

2. Ziakas NG, Woodruff G, Smith LK, Thompson JR. A study of heredity as a risk factor in strabismus. Eye. 2002;16(5):519-521.

3. Hu DN. Prevalence and mode of inheritance of major genetic eye diseases in China. J Med Genet. 1987;24(10):584-588.

4. Abrahamsson M, Magnusson G, Sjostrand J. Inheritance of strabismus and the gain of using heredity to determine populations at risk of developing strabismus. Acta Ophthalmol Scand. 1999;77(6):653-657.

5. Robaei D, Rose KA, Kifley A. Factors associated with childhood strabismus: findings from a population-based study. Ophthalmology. 2006; 113(7);1146-1153.

6. Donnelly UM, Stewart NM, Hollinger M. Prevalence and outcomes of childhood visual disorders. Ophthalmic Epidemiol. 2005;12(4): 243-250.

7. Awan HRA, Ahsan T. Prevalence of visual impairment and eye diseases in Afghan refugees in Pakistan. East Mediterr Health $J$. 1998;4(3);560-566.

8. Nisar Ahmed, Aamir AH, Iqbal Hussain, Shoukat Ghulam. Annual prevalence of various diseases in hospitalized patients in a tertiary level teaching hospital at Peshawar. PakJ Med Res. 2004;43(4):166-171.
9. Cooper J, Medow N. Major review: intermittent exotropia, basic anddivergence excess type. binocular vision. Eye Muscle Surgery Quarterly. 1993;8(3):185-216.

10. Keenan JM, Willshaw HE. Outcome of strabismus surgery in congenital esotropia. Br J Ophthalmol. 1992;76(6):342-345.

11. Willshaw HE, Keenen JM. Strabismus surgery in children: the prospects for binocular single vision. Eye. 1991;5(3):338-343.

12. Celebi S, Kukner AS. Large bilateral lateral rectus recession in large angle divergence excess exotropia. Eur J Ophthalmol. 2001;11(1): 6-8.

13. Livir-Rallatos G, Gunton KB, Calhoun JH. Surgical results in largeangle exotropia. J AAPOS. 2002;6(2):77-80.

14. Amitava AK, Goswami AK, Mishra A. Large-angle strabismus and primary true muscle transplantation. J Pediatr Ophthalmol Strabismus. 2005;42(4):211-215.

15. Currie ZI, Shipman T, Burke JP. Surgical correction of large-angle exotropia in adults. Eye. 2003;17(3):334-339.

16. Forrest MP, Finnigan S, Finnigan S, Gole GA. Three horizontal muscle squint surgery for large angle infantile esotropia. Clin Experiment Ophthalmol. 2003;31(6):509-516.

17. Ripart J, Lefrant JY, de La Coussaye JE, Prat-Pradal D, Vivien B, Eledjam JJ. Peribulbar versus retrobulbar anesthesia for ophthalmic surgery. Anesthesiology. 2001;94(1):56-62.

18. Greenberg MF, Pollard ZF. Adult strabismus surgery under propofol sedation with local versus general anesthesia. J AAPOS. 2003;7(2): $116-120$.

19. Hamilton RC. Complications of ophthalmic regional anesthesia. Ophthalmol Clin North Am. 1998;11:99-114.

20. Scott WE, Reese PD, Hirsh CR, Flabetich CA. Surgery for large angle congenital esotropia. Arch Ophthalmol. 1986;104:374-377.

21. Vroman DT, Hutchinson AK, Saunders RA, Wilson ME. Twomuscle surgery for congenital esotropia: rate of reoperation in patients with small versus large angles of deviation. J AAPOS. 2000;4(5): 267-270.

22. Prieto-Díaz J, Souza-Dias C. Esotropias. In: Prieto-Díaz, Souza-Dias C, editors. Estrabismo. São Paulo, Brasil; Livraria Santos Editora; 2002. p. 149-99.

23. Millán T, de Carvalho KM, Minguini N. Results of monocular surgery under peribulbar anesthesia for large-angle horizontal strabismus. Clinics. 2009;64(4):303-308.
Clinical Ophthalmology

\section{Publish your work in this journal}

Clinical Ophthalmology is an international, peer-reviewed journal covering all subspecialties within ophthalmology. Key topics include: Optometry; Visual science; Pharmacology and drug therapy in eye diseases; Basic Sciences; Primary and Secondary eye care; Patient Safety and Quality of Care Improvements. This journal is indexed on

\section{Dovepress}

PubMed Central and CAS, and is the official journal of The Society of Clinical Ophthalmology (SCO). The manuscript management system is completely online and includes a very quick and fair peer-review system, which is all easy to use. Visit http://www.dovepress.com/ testimonials.php to read real quotes from published authors. 